\title{
Marijuana Use and Depressive Symptoms among Young People: Examining Unidirectional and Bidirectional Effects
}

\author{
John P. Hoffmann \\ Department of Sociology, Brigham Young University, Provo, UT, USA \\ Email: john_hoffmann@byu.edu
}

How to cite this paper: Hoffmann, J.P. (2018) Marijuana Use and Depressive Symptoms among Young People: Examining Unidirectional and Bidirectional Effects. Health, 10, 1066-1078.

https://doi.org/10.4236/health.2018.108080

Received: May 31, 2018

Accepted: August 7, 2018

Published: August 10, 2018

Copyright $\odot 2018$ by author and Scientific Research Publishing Inc. This work is licensed under the Creative Commons Attribution International License (CC BY 4.0).

http://creativecommons.org/licenses/by/4.0/

Open Access

\begin{abstract}
Research suggests that the prevalence of marijuana use and depression are increasing in the United States. Although it is not entirely clear what accounts for these coincident trends, several studies have shown that these two health concerns are associated among young people. This study assessed four hypotheses regarding the association between marijuana use and depression: 1) whether marijuana use affects subsequent symptoms of depression; 2) whether depressive symptoms affect subsequent marijuana use; 3 ) whether they are associated in a bidirectional (reciprocal) manner; and 4) whether the association between the two is confounded by stressful life events. Using eight years of longitudinal data from the Family Wellness and Health Study, a fixed-effects regression model provided empirical support for the first hypothesis only, but not for the others. Future research should explore in greater detail why marijuana use may have a causal impact on experiences with depression among young people.
\end{abstract}

\section{Keywords}

Marijuana Use, Depressive Symptoms, Young People

\section{Introduction}

Recent studies have shown that the prevalence of marijuana use increased in the United States over the past decade [1] [2]. Among young adults, aged 18 - 29, the percentage reporting past-year marijuana increased from $17.7 \%$ in 2005 to $29.2 \%$ in 2015 [1]. Although the prevalence of use has remained steady among high school students, annual marijuana use among college students reached a level (39\%) not seen since the late 1980s [3]. 
The prevalence of depressive disorders has also been on the rise in the United States [4]. Past month prevalence among adults was about 10\% in 2017 [5], which is substantially higher than in $2002(6 \%)$ [6]. The prevalence of major depressive disorders (MDD) increased from $8.7 \%$ in 2005 to $11.3 \%$ in 2014 among adolescents, aged 12 - 17, and from $8.8 \%$ to $9.6 \%$ among young adults, aged 18 25 [7].

These coincident trends among young people are likely due to a host of structural, demographic, social, and psychological factors. Nonetheless, research has shown that there is a consistent individual-level association between marijuana use and depressive symptomatology [8] [9]. It is not clear, though, whether this association is causal in nature or due to confounding factors. Studies have provided evidence in support of several hypotheses, including that factors such as personal and interpersonal stressors affect the probability of both marijuana use and depressive symptoms (confounding hypothesis) [8] [9]; that more frequent marijuana use increases the risk of depressive symptoms [10] [11]; and that young people initiate or increase marijuana use following the onset or rise of depressive symptoms [12] [13]. The latter interpretation is warranted by the self-medication hypothesis: Negative emotional states such as those manifest in depressive symptoms motivate youth to use marijuana or other psychoactive substances to cope with or minimize these symptoms [13].

Although numerous studies have examined these hypotheses, there is little consensus regarding which one is most tenable. A recent review that may help adjudicate among them suggested that alcohol problems and major depression were linked in a causal manner, but that the most likely direction led from alcohol problems to depressive disorders because of metabolic and neurophysiological changes resulting from heavy alcohol use [14]. Another study found that heavy marijuana users manifest less dopamine response, which may affect the brain's reward region and lead to negative emotions, including, potentially, dysthymic or lugubrious states [15]. Yet these studies were limited to severe forms of substance use and depressive disorders, and focused primarily on small samples of adults. Moreover, few studies have considered that marijuana use and depressive symptoms may be part of a reciprocal causal loop, with each affecting the other in adolescence and young adulthood [16].

Given the lack of consensus regarding the association and sequencing of marijuana use and depressive symptoms among young people, the purpose of this study was to compare four hypotheses. The hypotheses are as follows:

H1: More frequent marijuana use is associated with more symptoms of depression.

H2: More symptoms of depression are associated with more frequent marijuana use.

H3: More frequent marijuana use and symptoms of depression are related reciprocally, with each reinforcing the other over time.

H4: Stressors affect the likelihood of both more frequent marijuana use and 
more symptoms of depression (confounding hypothesis).

The empirical test designed to compare these hypotheses used longitudinal data that followed a group of young people from adolescence to young adulthood (ages 11 - 23).

\section{Methods}

To examine the hypotheses, eight years of data (1991-1998) from the Family Wellness and Health Study (FWHS) were utilized [17] [18]. The FWHS was a prospective cohort (panel) survey conducted in a large, upper Midwestern U.S. metropolitan area that was designed to assess adolescent behavior and development. Families with adolescents were recruited from a variety of local mental health centers, regular health centers, and the general community. Eligibility criteria included the presence of at least one child, 10 - 14-years-old, in the home. Those who satisfied this criterion were invited to participate in the study along with their current and previous spouses or partners and their children in the specified age range. Recruitment took place over an 18-month time period. A total 861 children and adolescents and their parents agreed to participate. Following recruitment, parents and adolescents completed self-administered questionnaires on an annual basis. These were completed in a private setting, such as their homes, at an office, or an another convenient location. The questionnaires included extensive questions about stressful life events, depressive symptoms, and substance use using validated scales from previous research studies [19]-[25]. At the time of the first round of data collection, the adolescents were between 11 - and 15 -years-old (mean $=12.8)$. About $98 \%$ of respondents completed questionnaires during all eight years (840/861).

The sample included members of several birth cohorts in an accelerated longitudinal design [26], thus it was useful for testing the association between marijuana use and depressive symptoms among adolescents and young adults from ages 11 to 23 . This is an important period of the life course when substance use increases and decreases among many young people [27].

The sample members were mostly Caucasian (84\%), with the rest African-American (8\%) or members of other racial/ethnic groups (8\%). About half were females (49.3\%). The average age during year one was 12.8 and 20.1 during year eight. The average annual family income was close to $\$ 55,000$. Comparisons with U.S. Census Bureau data demonstrated that the FWHS sample was representative of the demographic distribution of the population in the local metropolitan area in terms of race, family income, parental education, family size, and family structure. The Institutional Review Boards of the university that sponsored this research and of the local health centers from which the respondents were recruited approved this study as satisfying human subjects protections.

\subsection{Outcome Variables}

Each year, the adolescent respondents were asked to report "On how many oc- 
casions (if any) have you used marijuana (grass, pot) or hashish (hash, hash oil) during the last 12 months?” The response options were from zero days (coded 0 ) to 40 or more days (coded 8). This inquiry was adapted from the Monitoring the Future study [19]. Since the coding strategy resulted is a substantially skewed variable, a Cox-Box transformation was used to normalize its distribution [28]. This reduced the skewness statistic of the marijuana use variable from 2.3 to 0.8 . It also led to residuals from the regression model that followed a normal distribution more closely than when the original metric was used.

The second outcome variable, depressive symptoms, was based on a set of questions asked each year from the revised CES depression scale, a 20-item inventory designed to assess the frequency of depressive symptomatology in a typical week during the previous 30 days [25]. The items included symptoms of sadness, restlessness, sleeplessness, inability to concentrate, suicidal or self-harm ideation, and poor appetite. The response categories were from 0 (zero days) to 4 (5 - 7 days). The responses were summed to create a depressive symptoms scale. Thus, the potential range of the variable was $0-80$, although the actual range was $0-45($ mean $=13.8$, s.d. $=11.7)$. In order to establish the temporal order of the outcome variables, each was measured at leading time points. In this way, the explanatory variables were used to predict subsequent marijuana use and depressive symptoms (e.g., $y_{t}=\beta_{0}+\beta_{\mathrm{xt}-1}+\varepsilon_{\mathrm{i}}$ ).

\subsection{Stressful Life Events}

A measure of stressful events was needed to assess hypothesis 4 . Researchers have classified stressful events as controllable or uncontrollable, which depends on the volition of the individual [29] [30]. Since depressive symptoms or marijuana use may lead to controllable events, such as poor relations or school problems, thus potentially confounding their causal association, and recent research indicates that uncontrollable experiences are the principal determinant of mental health problems [29], this study focused on largely uncontrollable events. These included past-year experiences such as parental mental health problems; parental divorce or separation; family financial problems; death, illness, or accidents among family or friends; and changes in school or residence. The events were measured each year by a checklist of 16 items derived from the Junior High Life Experiences Survey [20] and the Family Inventory of Life Events and Life Changes [21]. The actual number of life events reported by the respondents ranged from zero to 12 per year $($ mean $=1.8$; s.d. $=1.7)$.

\subsection{Control Variables}

Studies have demonstrated that several variables affect the associations among marijuana use, depressive symptoms, and stressful life events. For example, research suggests that self-esteem, self-efficacy, and positive family relationships attenuate the effects of stressful events on marijuana use or depressive symptoms [30] [31]. Therefore, measures of each of these, along with peer substance use, a 
common predictor of marijuana use [32], and several demographic covariates were included in the models.

Self-efficacy was measured during each year by Pearlin and Schooler's mastery [22] scale. This consisted of seven questions about perceived personal control over one's environment; in particular, a sense of helplessness, fatalism, and a lack of problem-solving ability. Since there was variation in the response patterns across years, each observed variable was standardized within year prior to creating additive scales. The standardization process consisted of taking the $z$-scores of each variable in each year. The $z$-scores were then added together to create the self-efficacy scale $($ mean $=0$; s.d. $=4.7)$. Higher scores on this scale indicated greater perceived control over life. The alpha coefficients for the annual scales ranged from $0.87-0.92$.

Self-esteem was gauged annually with Rosenberg's [23] 10-item scale. The questions inquired about respondents' feelings of worth, pride, ability, respect, and satisfaction with life. Higher values indicated higher self-esteem. Since there was variation in the response patterns of the self-esteem items across years, each was standardized within year prior to creating additive scales. The standardization process consisted of taking the $z$-scores of each variable in each year. The $z$-scores were then summed to create the self-esteem scale (mean $=0$; s.d $=6.9$ ). The alpha coefficients ranged from $0.82-0.88$.

Family relations were measured each year with 15 questions from the Family Adaptation and Cohesion Scale (FACES), which asked about family closeness, support, joint activities, and problem solving [24]. Each constituent variable was standardized within year prior to creating additive scales. The standardization process consisted of taking the $z$-scores of each variable in each year. The $z$-scores were then added together to create the family relations scale (mean $=0$, s.d. $=10.4)$. Higher scores on this scale specified better family relations. The alpha coefficients ranged from $0.80-0.92$.

Peer substance use was based on a set of questions that asked how often the respondents' three closest friends (friends could include siblings) engaged in the following types of substance use in the previous year: alcohol (use and been drunk), cigarettes, marijuana, and other types of illicit substance use. Responses to each question ranged from zero times (coded 0) to 31 or more times (coded 6). Additive scales demonstrated positive skew, so the natural logarithms of each $(+1)$ were taken to normalize their distributions $($ mean $=1.7$; s.d. $=1.2)$. The alpha coefficients ranged from $0.73-0.80$ across the eight years.

Studies have also found that patterns of marijuana use and depressive symptoms vary by several demographic characteristics [10] [12] [27] [30]. Thus, the following control variables were included in the model: family income $(1-12$, corresponding to increasing income levels; based on parents' reports) and family structure $(0=$ did not live with both parents, $1=$ lived with both parents). In addition, by the end of the observation period many respondents were young adults and a modest proportion had married, cohabited, or had a child. Since these life changes may affect the propensity to use marijuana or experience de- 
pressive symptoms [33], each year included dummy variables that indicated whether or not the respondent was married or cohabiting, or had a resident child. Finally, age was included in each model. Since preliminary analyses suggested that age had a quadratic association with depressive symptoms, both age and age-squared were included in the models.

Table 1 provides information about the distributions of all the variables used in the analysis. The standard deviations were decomposed into within-year and between-year components. Note that, for several of the variables, there was a similar degree of variability within and between years.

\subsection{Analysis}

The hypotheses were designed to compare four potential associations between marijuana use and depressive symptoms among young people. One of the hypotheses claimed that there are reciprocal associations between the two outcomes. Assessing reciprocal associations is complicated since the error terms of equations designed to predict two outcomes are not independent, thus failing to satisfy a key statistical assumption of most regression models. Another complication is that unobserved factors may confound any association between the two outcomes [34] [35].

In order to obviate each of these potential limitations, a fixed-effects regression model was estimated using an instrumental variables approach designed for longitudinal data [35]. Fixed-effects regression adjusts for unobserved invariant factors and thus can reveal causal patterns among time-varying explanatory and outcome variables [36]. Robust standard errors were estimated to minimize the risk of heteroscedasticity [37]. The explanatory variables were each measured in the year prior to the outcome variables to better establish their causal ordering. For example, in the equation designed to predict marijuana use, depressive symptoms, stressful life events, self-esteem, self-efficacy and the other covariates were measured at time $t-1$.

\section{Results}

The results of the fixed-effects models are presented in Table 2. The coefficients represent within-person changes in the outcome variables for each one-unit change in the explanatory variables [36] [37]. In general, the results provided support for hypothesis 1 and failed to support the other three hypotheses. Each one-unit increase in marijuana use was associated with a 1.75 increase in depressive symptoms relative to an individual's average depressive symptoms score. Although stressful life events were also associated with changes in marijuana use and depressive symptoms, they did not attenuate the effects of marijuana use on depressive symptoms (hypothesis 4). In addition, there was no evidence from the empirical model that depressive symptoms led to changes in subsequent marijuana use, thus indicating that neither hypothesis 2 nor 3 was supported.

The other results were consistent with previous research [9] [27] [30] [31] 
Table 1. Means and standard deviations (decomposed) of the outcome and explanatory variables, Family Wellness and Health Study.

\begin{tabular}{|c|c|c|c|c|c|}
\hline \multirow{2}{*}{$\begin{array}{c}\text { Variable } \\
\text { Past-year marijuana use }\end{array}$} & \multirow{2}{*}{$\begin{array}{c}\text { Mean } \\
0.18\end{array}$} & \multicolumn{2}{|c|}{ Decomposition of S.D. ${ }^{\mathrm{a}}$} & \multirow{2}{*}{$\begin{array}{c}\text { Minimum } \\
0\end{array}$} & \multirow{2}{*}{$\begin{array}{c}\text { Maximum } \\
0.9\end{array}$} \\
\hline & & 0.31 & overall & & \\
\hline & & 0.20 & between & & \\
\hline & & 0.25 & within & & \\
\hline \multirow[t]{3}{*}{ Depressive symptoms } & 13.77 & 11.67 & overall & 0 & 45 \\
\hline & & 8.38 & between & & \\
\hline & & 8.11 & within & & \\
\hline \multirow[t]{3}{*}{ Stressful life events } & 1.79 & 1.70 & overall & 0 & 12 \\
\hline & & 1.07 & between & & \\
\hline & & 1.35 & within & & \\
\hline \multirow[t]{3}{*}{ Age in years } & 15.47 & 2.77 & overall & 11 & 23 \\
\hline & & 2.17 & between & & \\
\hline & & 2.28 & within & & \\
\hline \multirow[t]{3}{*}{ Self-esteem } & 0.00 & 6.91 & overall & -37.45 & 11.75 \\
\hline & & 5.16 & between & & \\
\hline & & 4.68 & within & & \\
\hline \multirow[t]{3}{*}{ Self-efficacy } & 0.00 & 4.66 & overall & -22.98 & 9.14 \\
\hline & & 3.36 & between & & \\
\hline & & 3.32 & within & & \\
\hline \multirow[t]{3}{*}{ Family relations } & 0.00 & 10.44 & overall & -38.71 & 25.74 \\
\hline & & 8.02 & between & & \\
\hline & & 7.01 & within & & \\
\hline \multirow[t]{3}{*}{ Peer substance use (logged) } & 1.72 & 1.20 & overall & 0 & 4.48 \\
\hline & & 0.59 & between & & \\
\hline & & 1.05 & within & & \\
\hline \multirow[t]{3}{*}{ Family income } & 3.99 & 2.54 & overall & 1 & 12 \\
\hline & & 2.52 & between & & \\
\hline & & 0.12 & within & & \\
\hline \multirow[t]{3}{*}{ Lived with mother \& father } & 0.56 & 0.49 & overall & 0 & 1 \\
\hline & & 0.49 & between & & \\
\hline & & 0.04 & within & & \\
\hline \multirow[t]{3}{*}{ Married or cohabiting } & 0.04 & 0.21 & overall & 0 & 1 \\
\hline & & 0.13 & between & & \\
\hline & & 0.18 & within & & \\
\hline \multirow[t]{3}{*}{ Had a child } & 0.05 & 0.21 & overall & 0 & 1 \\
\hline & & 0.17 & between & & \\
\hline & & 0.16 & within & & \\
\hline
\end{tabular}

Note: the sample size is 840 , with eight observations per individual. The following variables are based on standardized summed scales: self-esteem, self-efficacy, and family relations. ${ }^{a}$ Because of the longitudinal nature of the study, the standard deviations are decomposed into between-year effects and within-year effects. The overall effects are also provided. The within- and between-year standard deviations are biased-corrected estimates. ${ }^{\mathrm{b}} \mathrm{A}$ Box-Cox transformation was used to normalize the variable's distribution. 
Table 2. Fixed-effects regression model of past-year marijuana use and past 30 day depressive symptoms, Family Wellness and Health Study.

\begin{tabular}{ccccc}
\hline \multirow{2}{*}{ Variable } & \multicolumn{2}{c}{ Marijuana use } & \multicolumn{2}{c}{ Depressive symptoms } \\
\cline { 2 - 5 } & Coefficient & Standard error & Coefficient & Standard error \\
\hline Marijuana use & - & - & $1.75^{* *}$ & 0.23 \\
Depressive symptoms & 0.08 & 0.06 & - & - \\
Stressful life events & $0.12^{\star}$ & 0.05 & $0.87^{\star}$ & 0.12 \\
Age & $0.17^{* *}$ & 0.02 & $-1.28^{* *}$ & 0.35 \\
Age & 0.03 & 0.02 & $-0.27^{*}$ & 0.12 \\
Self-esteem & 0.04 & 0.03 & $-0.15^{* *}$ & 0.03 \\
Self-efficacy & 0.03 & 0.02 & $-0.18^{* *}$ & 0.05 \\
Family relations & 0.01 & 0.01 & 0.12 & 0.19 \\
Peer substance use & $0.33^{* *}$ & 0.08 & $-0.75^{* *}$ & 0.25 \\
Family income & 0.01 & 0.01 & $-0.38^{* *}$ & 0.08 \\
Lived with both parents & $-0.05^{*}$ & 0.02 & 0.46 & 0.44 \\
Married/cohabiting & $0.06^{*}$ & 0.03 & -1.09 & 0.93 \\
Had a child & 0.09 & 0.14 & 0.66 & 0.92 \\
Intra-unit correlation & 0.35 & & 0.40 & \\
Residual correlation & & & $-0.33^{* *}$ & \\
\hline
\end{tabular}

Note: the sample size is 840 , with eight observations per individual. The results are from an instrumental variables fixed-effects regression model designed for longitudinal data. Robust standard errors are provided. The outcome variables are measured in the year following the explanatory variables. ${ }^{\star} \mathrm{p}<0.05$ (twotailed test). ${ }^{* *} \mathrm{p}<0.01$ (two-tailed test).

[32]. Higher levels of self-esteem and self-efficacy were associated with fewer depressive symptoms. Peer substance use led to increases in marijuana use over time. It was also associated with lower levels of depression, which may be indicative of how interpersonal associations, even with deviant peers, provide support that protects youth from issues of depression.

Fixed-effects regression models assume that the effects of time-invariant factors, which are not directly estimated by these models, do not change over time [36]. For example, variables such as gender and race/ethnicity are assumed to have the same influence on, say, depression and marijuana use regardless of the year or the age at which they are measured. One way to test this assumption is to introduce interaction terms between time-invariant factors and time-varying explanatory variables. Since research has suggested that the effects of stress and family relations on marijuana use and depression may differ by gender [38] [39], the models were extended to include interaction terms of each (e.g., sex $x$ stressful events). The results of this robustness check indicated that no interactions attained statistical significance, thus further justifying the use of the fixed-effects approach.

\section{Discussion}

This study was designed to examine the association between marijuana use and depressive symptoms across a period of the life course, adolescence and young 
adulthood, when significant changes are occurring among individuals. Previous studies suggested that marijuana use and depressive symptoms may be associated in a unidirectional or a bidirectional manner; or their association may be explained by stressful life experiences or other factors that are unobserved in most research studies. By using a fixed-effects model, each of these suppositions was tested. This empirical approach also has the advantage of adjusting for the effects of unobserved characteristics, thus moving closer to a causal representation.

The results showed clearly that the hypothesis presuming that increases in marijuana use lead to more symptoms of depression is tenable. There was no support for the other hypotheses, however. Depressive symptoms did not affect subsequent marijuana use, nor are these two outcomes part of a reciprocal loop. This supports previous research demonstrating that marijuana use increases the risk of depressive symptoms among young people [10] [11] [15]. Furthermore, the findings fail to support the self-medication hypothesis that proposes that marijuana use is a coping mechanism in the presence of depression or that it serves to alleviate symptoms [13]. Whereas some youth may self-medicate with illicit substances when depressed, the analysis suggested that this is not common enough to support a general self-medication hypothesis.

Of course, this is simply one study and, even though it provided clear evidence in support of one hypothesis, replication is necessary to confirm the presumed causal association between marijuana use and subsequent depressive symptoms [15]. Moreover, since the mechanisms that underlie the potential causal effects of marijuana use are not known at present, future studies should consider a broader range of explanatory variables, including those that gauge neurophysiological, neurochemical, genetic, and family history factors that place youth at risk of substance abuse and depressive symptomatology. In addition, the FWHS used in the analysis did not collect the sample in a random manner, so there are threats to external validity that should be considered. The FWHS was also not an ethnically or geographically diverse sample, thus the results have limited utility for considering the broader population of young people in the U.S. or elsewhere.

\section{Conclusion}

The present study provided evidence to support the proposition that more frequent use of marijuana increases the risk of depressive symptoms among young people. Yet it failed to support the notion that youth self-medicate with marijuana when they experience depressive symptoms. It also did not support the hypothesis that stressful events or other personal and interpersonal factors affect both marijuana use and depressive symptoms in such a way as to confound their association. On a more practical level, this calls for greater attention to preventing or minimizing marijuana use among young people since it may lead to mental health problems. This should be a special concern of health care providers given the recent trend to decriminalize or legalize marijuana in many states in 
the U.S. Although these policy initiatives apply to adult users only, prevention experts should also be concerned with whether they will result in more marijuana use among young people [40] [41].

\section{Acknowledgements}

I have benefitted from my collaborations on youth substance abuse and mental health issues with the late S. Susan Su, Felicia Gray Cerbone, Dean Gerstein, Robert Johnson, Hee-Choon Shin, and Scott Baldwin. Original funding for data collection was provided by grant DA05617 from the National Institute on Drug Abuse, USA. All interpretations of the results are the sole responsibility of the author.

\section{Author Contribution}

JP Hoffmann designed the study, performed all the analyses, and wrote the manuscript.

\section{Conflicts of Interest}

The authors declare no conflicts of interest regarding the publication of this paper.

\section{References}

[1] Kerr, W.C., Lui, C. and Ye, Y. (2018) Trends and Age, Period and Cohort Effects for Marijuana Use Prevalence in the 1984-2015 US National Alcohol Surveys. Addiction, 113, 473-481. https://doi.org/10.1111/add.14031

[2] Miech, R., Johnston, L. and O’Malley, P.M. (2017) Prevalence and Attitudes Regarding Marijuana Use among Adolescents over the Past Decade. Pediatrics, 140, e20170982. https://doi.org/10.1542/peds.2017-0982

[3] Sherburne, M. (2017) National Study Shows Marijuana Use among U.S. College Students at Highest Level in Three Decades. Institute for Social Research, University of Michigan, Ann Arbor, MI. http://home.isr.umich.edu/releases/mtf-marijuana-2017

[4] Weinberger, A.H., Gbedemah, M., Martinez, A.M., Nash, D., Galea, S. and Goodwin, R.D. (2017) Trends in Depression Prevalence in the USA from 2005 to 2015: Widening Disparities in Vulnerable Groups. Psychological Medicine, 48, 1308-1315. https://doi.org/10.1017/S0033291717002781

[5] Hasin, D.S., Sarvet, A.L., Meyers, J.L., Saha, T.D., Ruan, W.J., Stohl, M. and Grant, B.F. (2018) Epidemiology of Adult DSM-5 Major Depressive Disorder and Its Specifiers in the United States. JAMA Psychiatry, 75, 336-346. https://doi.org/10.1001/jamapsychiatry.2017.4602

[6] Kessler, R.C., Berglund, P., Demler, O., Jin, R., Koretz, D., Merikangas, K.R., Rush, A.J., Walters, E.E. and Wang, P.S. (2003) The Epidemiology of Major Depressive Disorder: Results from the National Comorbidity Survey Replication (NCS-R). JAMA, 289, 3095-3105. https://doi.org/10.1001/jama.289.23.3095

[7] Mojtabai, R., Olfson, M. and Han, B. (2016) National Trends in the Prevalence and Treatment of Depression in Adolescents and Young Adults. Pediatrics, 138, e20161878. https://doi.org/10.1542/peds.2016-1878 
[8] Keith, D.R., Hart, C.L., McNeil, M.P., Silver, R. and Goodwin, R.D. (2015) Frequent Marijuana Use, Binge Drinking and Mental Health Problems among Undergraduates. American Journal on Addictions, 24, 499-506. https://doi.org/10.1111/ajad.12201

[9] Low, N.C., Dugas, E., O’Loughlin, E., Rodriguez, D., Contreras, G., Chaiton, M. and O'Loughlin, J. (2012) Common Stressful Life Events and Difficulties are Associated with Mental Health Symptoms and Substance Use in Young Adolescents. BMC Psychiatry, 12, 116. https://doi.org/10.1186/1471-244X-12-116

[10] Lev-Ran, S., Roerecke, M., Le Foll, B., George, T.P., McKenzie, K. and Rehm, J. (2014) The Association between Cannabis Use and Depression: A Systematic Review and Meta-Analysis of Longitudinal Studies. Psychological Medicine, 44, 797-810. https://doi.org/10.1017/S0033291713001438

[11] Moore, T.H., Zammit, S., Lingford-Hughes, A., Barnes, T.R., Jones, P.B., Burke, M. and Lewis, G. (2007) Cannabis Use and Risk of Psychotic or Affective Mental Health Outcomes: A Systematic Review. The Lancet, 370, 319-328.

https://doi.org/10.1016/S0140-6736(07)61162-3

[12] Pang, R.D., Farrahi, L., Glazier, S., Sussman, S. and Leventhal, A.M. (2014) Depressive Symptoms, Negative Urgency and Substance Use Initiation in Adolescents. Drug \& Alcohol Dependence, 144, 225-230. https://doi.org/10.1016/j.drugalcdep.2014.09.771

[13] Hooshmand, S., Willoughby, T. and Good, M. (2012) Does the Direction of Effects in the Association between Depressive Symptoms and Health-Risk Behaviors Differ by Behavior? A Longitudinal Study across the High School Years. Journal of Adolescent Health, 50, 140-147. https://doi.org/10.1016/j.jadohealth.2011.05.016

[14] Boden, J.M. and Fergusson, D.M. (2011) Alcohol and Depression. Addiction, 106, 906-914. https://doi.org/10.1111/j.1360-0443.2010.03351.x

[15] Volkow, N.D., Wang, G.J., Telang, F., Fowler, J.S., Alexoff, D., Logan, J., Jayne, M., Wong, C. and Tomasi, D. (2014) Decreased Dopamine Brain Reactivity in Marijuana Abusers Is Associated with Negative Emotionality and Addiction Severity. Proceedings of the National Academy of Sciences, 111, E3149-E3156. https://doi.org/10.1073/pnas.1411228111

[16] Marmorstein, N.R. (2009) Longitudinal Associations between Alcohol Problems and Depressive Symptoms: Early Adolescence through Early Adulthood. Alcoholism: Clinical and Experimental Research, 33, 49-59. https://doi.org/10.1111/j.1530-0277.2008.00810.x

[17] Hoffmann, J.P., Baldwin, S.A. and Cerbone, F.G. (2003) Onset of Major Depressive Disorder among Adolescents. Journal of the American Academy of Child \& Adolescent Psychiatry, 42, 217-224. https://doi.org/10.1097/00004583-200302000-00016

[18] Hoffmann, J.P. (2010) A Life-Course Perspective on Stress, Delinquency, and Young Adult Crime. American Journal of Criminal Justice, 35, 105-120. https://doi.org/10.1007/s12103-010-9072-4

[19] Bachman, J.G., Johnston, L.D., O’Malley, P.M., Schulenberg, J.E. and Miech, R.A. (2015) The Monitoring the Future Project after Four Decades: Design and Procedures. Institute for Social Research, University of Michigan, Ann Arbor. http://monitoringthefuture.org/pubs/occpapers/mtf-occ82.pdf

[20] Swearingen, E.M. and Cohen, L.H. (1985) Measurement of Adolescents' Life Events: The Junior High Life Experiences Survey. American Journal of Community Psychology, 13, 69-85. https://doi.org/10.1007/BF00923260

[21] Lavee, Y., McCubbin, H.I. and Olson, D.H. (1987) The Effect of Stressful Life Events 
and Transitions on Family Functioning and Well-Being. Journal of Marriage and the Family, 49, 857-873. https://doi.org/10.2307/351979

[22] Pearlin, L.I. and Schooler, C. (1978) The Structure of Coping. Journal of Health and Social Behavior, 19, 2-21. https://doi.org/10.2307/2136319

[23] Rosenberg, M. (1979) Conceiving the Self. Basic Books, New York.

[24] Olson, D. (2011) FACES IV and the Circumplex Model: Validation Study. Journal of Marital and Family Therapy, 37, 64-80. https://doi.org/10.1111/j.1752-0606.2009.00175.x

[25] Van Dam, N.T. and Earleywine, M. (2011) Validation of the Center for Epidemiologic Studies Depression Scale-Revised (CESD-R): Pragmatic Depression Assessment in the General Population. Psychiatry Research, 186, 128-132. https://doi.org/10.1016/j.psychres.2010.08.018

[26] Galbraith, S., Bowden, J. and Mander, A. (2017) Accelerated Longitudinal Designs: An Overview of Modelling, Power, Costs and Handling Missing Data. Statistical Methods in Medical Research, 26, 374-398. https://doi.org/10.1177/0962280214547150

[27] Bachman, J.G., Wadsworth, K.N., O’Malley, P.M., Johnston, L.D. and Schulenberg, J.E. (2013) Smoking, Drinking, and Drug Use in Young Adulthood: The Impacts of New Freedoms and New Responsibilities. Psychology Press, New York.

[28] Ryan, T.P. (2008) Modern Regression Methods. New York, Wiley. https://doi.org/10.1002/9780470382806

[29] Boardman, J.D., Alexander, K.B. and Stallings, M.C. (2011) Stressful Life Events and Depression among Adolescent Twin Pairs. Biodemography and Social Biology, 57, 53-66. https://doi.org/10.1080/19485565.2011.574565

[30] Hoffmann, J.P. (2016) Cumulative Stress and Substance Use from Early Adolescence to Emerging Adulthood. Journal of Drug Issues, 46, 267-288. https://doi.org/10.1177/0022042616638492

[31] Tate, S.R., Wu, J., McQuaid, J.R., Cummins, K., Shriver, C., Krenek, M. and Brown, S.A. (2008) Comorbidity of Substance Dependence and Depression: Role of Life Stress and Self-Efficacy in Sustaining Abstinence. Psychology of Addictive Behaviors, 22, 47-57. https://doi.org/10.1037/0893-164X.22.1.47

[32] Epstein, M., Hill, K.G., Roe, S.S., Bailey, J.A., Iacono, W.G., McGue, M., Kristman-Valente, A., Catalano, R.F. and Haggerty, K.P. (2017) Time-Varying Effects of Families and Peers on Adolescent Marijuana Use: Person-Environment Interactions across Development. Development and Psychopathology, 29, 887-900. https://doi.org/10.1017/S0954579416000559

[33] Musick, K. and Bumpass, L. (2012) Reexamining the Case for Marriage: Union Formation and Changes in Well-Being. Journal of Marriage and Family, 74, 1-18. https://doi.org/10.1111/j.1741-3737.2011.00873.x

[34] Brüderl, J. and Ludwig, V. (2015) Fixed-Effects Panel Regression. In: Best, H. and Wolf, C., Eds., The Sage Handbook of Regression Analysis and Causal Inference, Sage, Thousand Oaks, 327-357.

[35] Hsiao, C. (2014) Analysis of Panel Data. 3rd Edition, Cambridge University Press, New York. https://doi.org/10.1017/CBO9781139839327

[36] Allison, P.D. (2009) Fixed Effects Regression Models. Sage, Thousand Oaks. https://doi.org/10.4135/9781412993869

[37] Hoffmann, J.P. (2016) Regression Models for Categorical, Count, and Related Variables. University of California Press, Oakland. 
[38] Hankin, B.L., Young, J.F., Abela, J.R., Smolen, A., Jenness, J.L., Gulley, L.D., Technow, J.R., Gottlieb, A.B., Cohen, J.R. and Oppenheimer, C.W. (2015) Depression from Childhood into Late Adolescence: Influence of Gender, Development, Genetic Susceptibility, and Peer Stress. Journal of Abnormal Psychology, 124, 803-816. https://doi.org/10.1037/abn0000089

[39] Schuster, R.M., Mermelstein, R. and Wakschlag, L. (2013) Gender-Specific Relationships between Depressive Symptoms, Marijuana Use, Parental Communication and Risky Sexual Behavior in Adolescence. Journal of Youth and Adolescence, 42, 1194-1209. https://doi.org/10.1007/s10964-012-9809-0

[40] Ammerman, S., Ryan, S., Adelman, W.P. and Committee on Substance Abuse (2015) The Impact of Marijuana Policies on Youth: Clinical, Research, and Legal Update. Pediatrics, 135, e769-e785. https://doi.org/10.1542/peds.2014-4147

[41] Joffe, A. (2017) Understanding the Full Effect of the Changing Legal Status of Marijuana on Youth: Getting It Right. JAMA Pediatrics, 171, 115-116.

https://doi.org/10.1001/jamapediatrics.2016.3920 